abrupt shifts. in gear can be upsetting, especially as they are hidden by Casti's easy style, which can cause one to exceed the speed limit. The book deserves to be taken at leisure. Breezing too rapidly through Reality Rules, one might get the impression that it really reels.

Like most travel guides, the book does not recoil from hype; but it is used in a relaxed way, secure in the confidence that if readers don't buy one cruise, they'll book another. This nonchalance reflects the current trend away from theories toward models. A theory can have supporters and opponents, each committed to the hilt; but a model cannot cause fanaticism - you're free to take it or leave it in the tolerant eclecticism of the Roman Pantheon. Casti is no button-holing zealot out to convince. In fact, his lines are studded (artfully, I suspect) with casual asides meant to provoke even the most docile of readers into occasional mutterings, containing such off-handed remarks as that Western science arose because the 'competition' was unable to come up with a satisfactory explanation of the Black Death, and claiming that some innocuous incidence matrix yields 'insight' into a Shakespearean sonnet. But these are minor eddies in a broad stream; the tale runs smoothly on, and carries such a wealth of information that one doesn't feel like quibbling over matters of opinion with such an urbane cicerone. As a racy synopsis covering a huge area, Reality Rules will best be enjoyed by scientists who have retained not just a working knowledge of college mathematics, but also a youthful taste for the excitement of heady intellectual adventure.

Karl Sigmund is in the Institute for Mathematics, University of Vienna, Strudlhofgasse 4, A-1090 Vienna, Austria.

\title{
Symmetry for the armchair
}

\section{Simon L. Altmann}

Symmetry in Chaos: A Search for Pattern In Mathematics, Art and Nature. By Michael Field and Martin Golubitsky. Oxford University Press: 1992. Pp. 218. $£ 19.95, \$ 35$.

Reflections on Symmetry in Chemistry... and Elsewhere. By Edgar Heilbronner and Jack D. Dunitz. VCH: 1993. Pp. 154. DM58, £22.

The Dynamics of Ambiguity. By Giuseppe Caglioti. Springer: 1992. Pp. 170. DM98, $£ 40$.

EVER since Hermann Weyl published his famous Symmetry in 1952 many have been called to write on the subject; few, however, are those who can move, like Weyl, with equal authority from Hans Castorp to the problem of inversion in Raphael's cartoons. In Symmetry in Chaos, Michael Field and Martin Golubitsky, quite wisely, have given themselves a different remit and have succeeded in producing a book that is in itself a work of art: not a minor achievement for a book on mathematics. They have in fact invented a wonderful scheme to produce two-dimensional coloured patterns by computer.

If you allow your cursor to perform a random walk, pixel by pixel, on a computer screen and if you have a colour scale in which the pixel colour is determined by the number of visits that it has received, you will of course get, after sufficient iteration, a uniformly coloured rectangle. Field and Golubitsky, instead, superimpose on this process an attractor, in the sense of chaos theory. This is an iteration scheme that will guide the ac670

joined the ranks of the great inventors of two-dimensional patterns, from the craftsmen of the Alhambra to the modern ceramic, textile and wallpaper designers.

A general book on symmetry that does not quote or reproduce $M$. C. Escher is a rare one these days and Field and Golubitsky's is no exception to the rule. But in Reflections on Symmetry in Chemistry... and Elsewhere, Edgar Heilbronner and Jack D. Dunitz go further, because they are the first people I know of to point out that patterns in which the background is a translated mirror image of the foreground were in fact invented by Kolo Moser decades before Escher. Anyone fortunate enough to gain access to the recently refurbished (but alas still erratically open) Museum für Angewandte Kunst in Vienna can see a cabinet by Moser with a marquetry frieze where the positive and negative layers are identical after reflection (in practice, a 180-degree rotation about an axis on the layer) and translation. It is possible that the challenge to achieve this in marquetry drove Moser's invention, but he also used the idea in textile design.

This detail in Heilbronner and Dunitz's book is typical of the meticulous care with which it has been written. Without any mathematics, the more important ideas arising from group theory are given and beautifully



Swirling Streamers taken from Symmetry In Chaos. illustrated. To achieve such a degree of informed simplicity is indeed most difficult and the authors even succeed in explaining sufficiently the concept of irreducible representation so as to be able to discuss Woodward and Hoffmann's rules. But there is a great deal more in this excellent work, from very illuminating symmetry games to historical discussions on the use of symmetry principles. This is a book that one can warmly recommend to intelligent sixth-formers and undergraduates alike.

Such an audience, however, cannot easily be imagined for The Dynamics of Ambiguity by

tion of the mathematics to make their method understandable, as well as the ideas behind it, and full programs in BASIC are given in the appendices. As the authors themselves say, the question whether these pictures, and the underlying mathematics, will be of lasting scientific interest "is one that has yet to be answered". These two mathematicians, on the other hand, have now
Giuseppe Caglioti, now translated from the Italian by A. O. Bucci. But none of its readers will fail to be struck by the width of the author's interest in broken symmetries, from quantum mechanics, music and art analysis à la Arnheim, to Virgil's poetry.

Simon L. Altmann is at Brasenose College, Oxford OX1 4A, UK.

NATURE · VOL $362 \cdot 15$ APRIL 1993 